\title{
DIAGNÓSTICO E PROAGNÓSTICO DOS RSU PARA MUNICÍPIO DE SANANDUVA/RS
}

\author{
M. FRACASSO'; R. M. DALEPIANE'; M. R. M H. PORSCH²; E. E. Pfuller ${ }^{2}$ e R. S. SILVA ${ }^{2}$ \\ Tecnólogo em Gestão Ambiental - Universidade Estadual do Rio Grande do Sul \\ Docente - Universidade Estadual do Rio Grande do Sul \\ marilia_bio@hotmail.com*
}

Submetido 13/11/2015 - Aceito 25/07/2017

DOI: $10.15628 /$ holos.2017.3699

\section{RESUMO}

A falta de uma gestão adequada dos resíduos sólidos urbanos (RSU) tem provocado ao longo dos anos nos Municípios com menos de vinte mil habitantes, diversos prejuízos nas áreas da saúde pública, equidade social e conservação ambiental, além de impactos significativos na ordem econômica em diversos segmentos de atividade. Dentro deste contexto, é necessária a efetiva implantação das diretrizes que preconizam a Política Nacional de Resíduos Sólidos. Com isso, o objetivo deste trabalho foi realizar o diagnóstico e o prognóstico para a gestão de resíduos sólidos urbanos (RSU) do município de Sananduva/RS, e como a proposta de novos métodos de gerenciamento de RSU pode contribuir na redução e adequada destinação de RSU. A metodologia deste trabalho foi dividida em três etapas: revisão literária do tema, avaliação da situação atual de gerenciamento de resíduos sólidos e a análise e cruzamento dos dados obtidos. Os resultados obtidos demonstram que a população urbana do município de Sananduva/RS, no período de set/2012 a ago/2013 teve uma geração de $3.577 .440 \mathrm{~kg}$ de RSU, o que representa uma produção per capita $0,919 \mathrm{~kg} . \mathrm{hab}^{-1} \cdot \mathrm{d}^{-1}$ de RSU. Com isto, verifica-se a necessidade da inserção de novas técnicas de tratamento final dos RSU, como a compostagem, coleta seletiva/logística reversa e incineração, aliadas a efetiva conscientização ambiental da população, buscando mudanças de hábitos sustentáveis.

PALAVRAS-CHAVE: Resíduos Sólidos Urbanos; Gestão; Meio Ambiente.

\section{DIAGNOSTIC AND PROGNOSTIC FOR THE MUNICIPALITY OF SANANDUVA/RS}

\begin{abstract}
Lack of proper management of municipal solid waste (MSW) has resulted over the years in the municipalities with less than twenty thousand inhabitants, many losses in the areas of public health, social equity and environmental conservation with significant impacts on economic order various activity segments. Within this context, the effective implementation of the guidelines that prioritize the National Policy on Solid Waste is required. Thus, the objective of this work was to make the diagnosis and prognosis for the management of municipal urban solid waste (MSW) in the municipality of Sananduva/RS, and as the proposal of new MSW management methods can contribute to the reduction
\end{abstract}

and proper disposal of RSU. The methodology of this study was divided into three steps: literature review of the topic, assessment of the current situation of solid waste management and analysis the data obtained. The results show que the urban population of the municipality of Sananduva/RS, on the set of period aug/2012 to set/2013, had a generation of 3,577,440 kg of MSW, Which Represents the per capita production $0919 \mathrm{~kg} \cdot \mathrm{hab}^{-1} \cdot \mathrm{d}^{-1}$ of MSW. Thus, the need to insert of new techniques for final treatment of municipal MSW, such as composting, selective collection/reverse logistics and incineration, combined with effective environmental awareness of the population, seeking sustainable habits.

KEYWORDS: Urban Solid Waste; Management; Environment. 


\section{INTRODUÇÃO}

O acelerado processo de urbanização trouxe novos desafios para a organização das cidades, associada a elevação da produção de novos materiais, produtos e serviços, o sucateamento e o descarte deste, vem favorecendo ao acúmulo dos chamados Resíduos Sólidos Urbanos (RSU). No Brasil, os RSU são definidos pela Associação Brasileira de Normas Técnicas por meio da Norma Brasileira Regulamentadora (ABNT NBR) 10.004 (2004), como aqueles resíduos nos estados sólido e semissólido, que resultam de atividades de interferência antrópica originadas de processos industriais, domésticos, hospitalares, comerciais, agrícolas e de serviços. Após o consumo estes materiais são encaminhados para o descarte em "lixões", aterros controlados ou sanitários, ficando sob a responsabilidade do poder público municipal. Contudo, a disposição inadequada decorrente da produção excessiva de resíduos de consumo, os transformam em um dos principais problemas urbanos nos últimos anos.

Dentre os resíduos que podem ser destacados atualmente, seja pela quantidade gerada como pela sua complexidade, inclui-se o grupo de resíduos sólidos urbanos (RSU), mais comumente conhecidos como "lixo". Os RSU são gerados, em sua grande maioria, pela população e armazenados temporariamente em sacos plásticos, que são depositados geralmente em coletores conhecidos com "lixeiras", contêineres e até mesmo no passeio público ou terrenos baldios, para que o serviço de coleta municipal encaminhe para um destino nem sempre adequado. Na maioria das vezes a população desconhece o destino dos RSU, pois a partir do momento em que o mesmo é assumido pelo município, considera-se que este material não é mais de sua responsabilidade.

A problemática no que tange ao gerenciamento adequado dos RSU, principalmente a falta de planejamento desta, poderá acarretar em problemas de saúde pública, ocupacional e ambiental e também de ordem econômica em diversos segmentos. Dentro deste contexto, fez-se necessário a regulamentação de uma Política Nacional de Resíduos Sólidos (PNRS), instituída através da Lei n. 12.305 (2010) e a Lei n. 11.445 (2007). Este marco regulatório harmoniza-se com diversas outras legislações, que compõe o arcabouço legal que influenciará na postura da totalidade dos agentes envolvidos no ciclo de vida dos materiais e produtos utilizados nas atividades antrópicas na atualidade (Mazzer \& Cavalcanti, 2004).

É público e notório que a geração de resíduos está intimamente relacionada ao crescimento da população e das cidades, incluindo o desenvolvimento das indústrias e a produção de bens de consumo, o que vem trazendo grandes desafios às administrações públicas, no que tange a gestão de RSU. A presença dos RSU como parte integrante e inevitável na vida do homem, o qualifica como um importante agente de interação nos mais diversos setores de atividade. A partir de uma visão holística, os resíduos sólidos relacionam-se com questões como energia, educação, saúde e saneamento, recursos naturais, geração de renda e empregos, turismo e recreação, direito e cidadania, meio ambiente.

Os RSU são, sem dúvida, uns dos principais problemas das sociedades contemporâneas, como resultado de uma acelerada urbanização, mudanças comportamentais e altos níveis de consumo. Em média, estima-se que cada brasileiro gere entre 0,5 a 1,0 kg de resíduo por dia, sendo a maior parte deste depositado diretamente no solo, com o mínimo ou nenhum controle 
de disposição ou tratamento, provocando sérios danos ao ecossistema e expondo a população a diversos riscos (ABRELPE, 2013).

Por outro lado, o descarte adequado dos RSU, por meio de atividades como o Gerenciamento Integrado de Resíduos Sólidos Urbanos (GIRS), contribui para a redução dos impactos ambientais. Porém, essa atividade ainda representa um desafio para as cidades de pequeno porte, devido à carência de recursos tecnológicos, financeiros e humanos qualificados. Nessa perspectiva, o GIRS corresponde ao processo que envolve diferentes órgãos da administração pública e da sociedade civil, devendo ser uma meta de compromisso social, para que se realize a limpeza urbana, a coleta, o tratamento e a disposição final de RSU. Para tanto, a sociedade precisa ser estimulada a reduzir a quantidade de resíduos produzidos, de modo que, se possa elevar sua qualidade de vida e promover um mundo ambientalmente saudável.

\section{REVISÃO BIBLIOGRÁFICA}

\subsection{Resíduos Sólidos Urbanos}

A ABNT NBR 10.004 de 2004 e a PNRS sob a Lei n. 12.305 (2010), definem resíduos sólidos como:

Resíduos nos estados sólido e semi-sólidos, que resultam das atividades da comunidade de origem: industrial, domiciliar, hospitalar, comercial, agrícola, de serviços e de varrição. Ficam incluídos nesta definição os lodos provenientes de sistemas de tratamento de água, aqueles gerados em equipamentos e instalações de controle de poluição, bem como determinados líquidos, cujas particularidades tornem inviável o seu lançamento na rede pública de esgotos ou corpos d'água ou exijam para isso soluções técnicas e economicamente inviáveis em face à melhor tecnologia disponível.

De acordo com Sandrini (2005) o resíduo é definido como os restos das atividades humanas, consideradas pelos geradores como inúteis, indesejáveis ou descartáveis. Estes, normalmente, apresentam-se sob o estado sólido, semi-sólido ou semi-líquido. A falta de gerenciamento destes resíduos associados a uma precária educação ambiental faz aumentar ainda mais a degradação e a agressão ao meio ambiente, no qual vivemos, colocando em risco os recursos naturais, vitais à nossa sobrevivência, afetando a saúde, o bem-estar e a segurança das populações.

As definições de resíduos e rejeitos diferem conforme a situação em que seja aplicada. 0 resíduo é todo material sólido não utilizado nas atividades produtivas, as sobras. O lixo é todo material sólido considerado como inútil ou descartável pelo proprietário. E o rejeito é todo material sólido que passa por um processo de seleção e é excluído (Calderoni, 2003).

Segundo o Zveibil et al. (2001), resíduo é aquilo que não tem valor comercial. Neste caso, pouca coisa jogada fora pode ser chamada de lixo, pois muitos materiais já podem ser reaproveitados e, por isso, tem valor. No entanto, para Lima (2004) resíduo é um conjunto heterogêneo de elementos desprezados durante um dado processo e, pela forma como é tratado, assume um caráter depreciativo, sendo associado à sujeira, repugnância, pobreza, falta de educação e outras conotações negativas. 
Para Zveibil et al. (2001) conceituar lixo ou resíduo sólido não é tão simples, pois sua definição pode ser bastante variada, pois o que é considerado lixo para alguns pode ser reutilizado ou reaproveitado para outros.

\subsection{Classificação de RSU}

Conforme Consoni \& Gonzalez (2000) os resíduos podem ser classificados quanto a sua origem:

- Domiciliar: constituído de restos de alimentação, invólucros diversos, varreduras, folhagem, ciscos, produtos deteriorados, jornais, garrafas, embalagens em geral, papel higiênico, fraldas descartáveis, e uma grande diversidade de outros itens. Contém ainda alguns resíduos que podem ser tóxicos, como as pilhas e lâmpadas por conterem materiais pesados que podem migrar e integrar-se à cadeia alimentar do homem, e os frascos de aerossóis que contém restos de substâncias químicas perigosas.

- Comercial: proveniente de diversos estabelecimentos comerciais inclui forte componente de papel, plásticos, embalagens diversas e resíduos de asseio dos funcionários, tais como papéis toalhas, papel higiênico, etc.

- Público: antes considerados como feria, varrição e outros, constituindo-se de papéis, cigarros, restos de capinação, folhas, etc.

- Serviços de saúde e hospitalar: constituem os resíduos sépticos, ou seja, que contêm ou potencialmente podem conter germes patogênicos. São produzidos em serviços de saúde, tais como: hospitais, clínicas, farmácias, laboratórios, etc. São agulhas, seringas, algodões, órgãos e tecidos removidos, meios de cultura e animais usados em testes, sangue coagulado, luvas descartáveis, etc. Resíduos assépticos do local como papéis, restos de alimentos, e outros que não entram em contato direto com pacientes ou com os resíduos sépticos são considerados como domiciliares.

- Portos, aeroportos, terminais rodoviários e ferroviários: resíduos originados de material de higiene, asseio pessoal e restos de alimentação que podem veicular doenças de outras cidades, estados e países. Estes resíduos podem ser potencialmente vetores de germes patogênicos, trazidos aos portos, terminais rodoviários e aeroportos.

- Industrial: bastante variado, podendo ser representado por cinzas, lodos, óleos, resíduos alcalinos ou ácidos, plásticos, papel madeira, fibras, borrachas, cerâmicas, etc. incluindo a grande maioria do resíduo considerado tóxico.

- Agrícola: resíduos sólidos das atividades agrícolas e da pecuária, como embalagens de adubos, defensivos agrícolas, ração, etc. Também as embalagens de agroquímicos, em geral, altamente tóxicos.

- Entulhos: são resíduos da construção civil, originados em demolição e restos de obras, solos de escavações, etc. geralmente é um material inerte, passível de reaproveitamento.

\subsection{Situação dos Resíduos Sólidos no Brasil e no Rio Grande do Sul}

Os últimos cinquenta anos o Brasil se transformou de país agrário em um país urbano, concentrando, em 2010 , mais de $85 \%$ da sua população nas áreas urbanas. O crescimento das cidades brasileiras não foi acompanhado pela provisão de infraestrutura e de serviços urbanos, 
entre eles os serviços públicos de saneamento básico, que envolvem o abastecimento de água potável, coleta e tratamento de esgoto sanitário, estrutura para a drenagem urbana e o sistema de gestão e manejo dos resíduos sólidos (MMA, 2011). O resultado desse crescimento desordenado reflete a condição de grande parte das políticas urbanas no país, as quais estão muito aquém das práticas consideradas sustentáveis.

De acordo com Panorama dos Resíduos Sólidos (2013), a geração de RSU no Brasil registrou crescimento de 4,1\%, de 2012 para 2013, índice percentual que é superior à taxa de crescimento populacional urbano do país, que foi de $3,7 \%$ no mesmo período, conforme demonstram os dados apresentados na Figura 1. O aumento observado segue tendência constatada nos anos anteriores, porém cada vez maior.

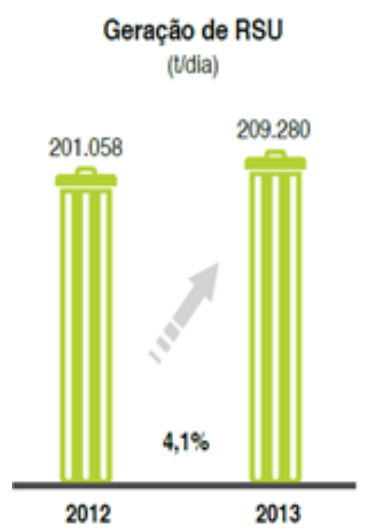

Geração de RSU per capita (Kghab.dila)

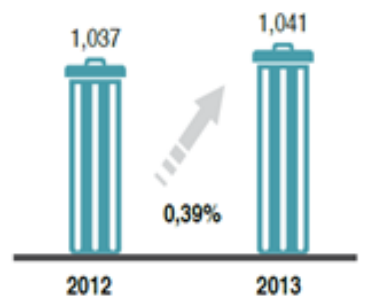

Figura 1: Geração de Resíduos Sólidos Urbanos no Brasil - 2012 e 2013. Fonte ABRELPE (2013).

A partir da quantidade total gerada de resíduos em 2013, 9,58\% de RSU deixaram de ser coletadas no ano de 2013 e, por consequência, tiveram destino impróprio ou inadequado. O Brasil, com uma população de 201.062.789 habitantes, produziu no ano de 2013, 209.280 t/dia de RSU, totalizando 76.387.200 t/ano. A geração de resíduos per capita foi de 1, $041 \mathrm{~kg} / \mathrm{hab} . / \mathrm{dia}$. A Figura 2 apresenta as porcentagens de coleta de resíduos sólidos, nas cinco regiões do país. Conforme Figura 2, a região sul corresponde a 10,9\% do total de resíduos sólidos produzidos no Brasil no ano de 2013 (PANORAMA DOS RESÍDUOS SÓLIDOS, 2013).

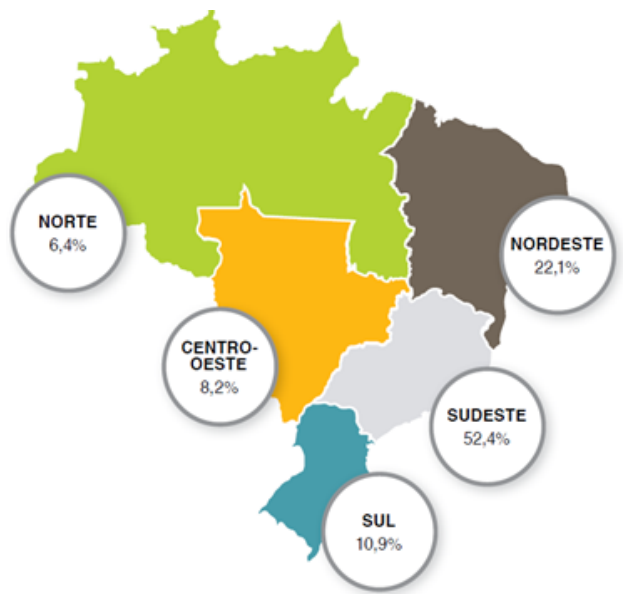

Figura 2: Porcentagem de coleta dos RSU por região do Brasil. Fonte Fonte ABRELPE (2013). 
A composição gravimétrica média, de acordo com o Plano Nacional de Resíduos Sólidos (2012), é de $51,4 \%$ de matéria orgânica, 31,9\% de materiais recicláveis e $16,7 \%$ de outros materiais, conforme Figura 3 a seguir.

Esta composição é bastante diversificada nas diferentes regiões, uma vez que está diretamente relacionada com características, hábitos e costumes de consumo e descarte da população local.

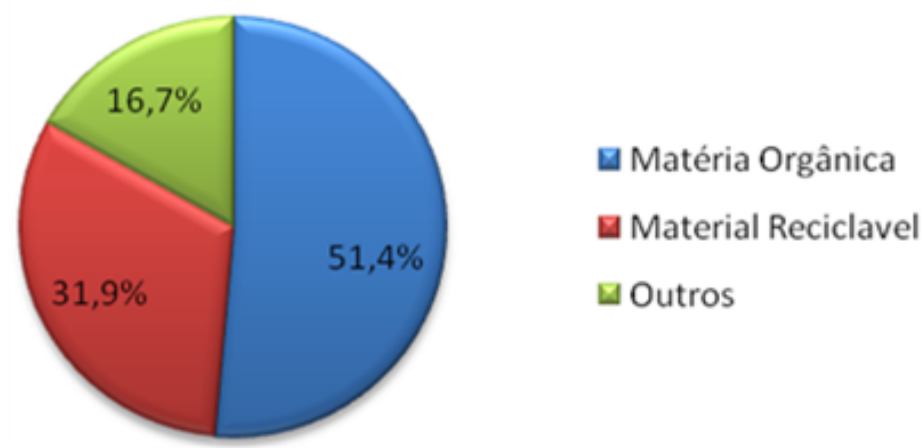

Figura 3: Composição média gravimétrica dos RSU - Brasil. Fonte: ABRELPE 2012

Esta composição é bastante diversificada nas diferentes regiões, uma vez que está diretamente relacionada com características, hábitos e costumes de consumo e descarte da população local.

A região sul com seus 1.191 municípios produziu no ano de 2013, aproximadamente de 21.922 toneladas/dia de RSU, das quais $94,1 \%$ foram coletadas, este valor gerado, resulta em uma produção de $0,761 \mathrm{~kg} / \mathrm{hab} . /$ dia.

O estado do Rio Grande do Sul, com uma população de 11.164 .043 habitantes, produziu neste período 8.485 t/dia, totalizando 3.054 .600 t/ano. A geração de resíduos per capita foi de 0 , 712 kg/hab./dia, conforme pode ser observado na Tabela 1.

Tabela 1 - Coleta e Geração RSU no Rio Grande do Sul (2012-2013).

\begin{tabular}{|c|c|c|c|c|c|c|c|}
\hline \multirow{2}{*}{\multicolumn{2}{|c|}{ População Total }} & \multicolumn{4}{|c|}{ RSU Coletado } & \multirow{2}{*}{\multicolumn{2}{|c|}{ RSU Gerado (t/dia) }} \\
\hline & & \multicolumn{2}{|c|}{$\left(\right.$ kg.hab $^{-1} \cdot$ dia $\left.^{-1}\right)$} & \multicolumn{2}{|c|}{ (t/dia) } & & \\
\hline 2012 & 2013 & 2012 & 2013 & 2012 & 2013 & 2012 & 2013 \\
\hline 10.770 .603 & 11.164 .043 & 0,709 & 0,712 & 7.635 & 7.953 & 8.225 & 8.485 \\
\hline
\end{tabular}

Fonte: ABRELPE 2013.

Na Figura 4 pode-se observar que 70,2\% dos RSU gerados do Rio Grande do Sul tiveram como destino final os aterros sanitários. Também cerca de $12,2 \%$ dos resíduos ainda são descartados em locais inadequados, no caso em lixões. 


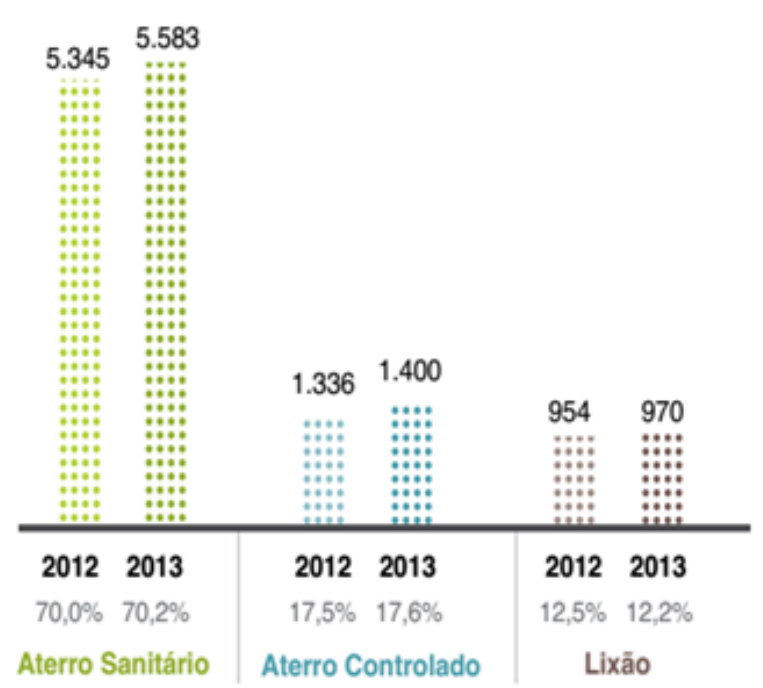

Figura 4: Destinação dos RSU em toneladas no Rio Grande do Sul (2012-2013). Fonte ABRELPE (2013).

\section{METODOLOGIA}

O método de pesquisa, segundo Lakatos \& Marconi (1991) constitui-se em um conjunto de atividades sistemáticas e racionais, que orientem a geração de conhecimentos válidos e verdadeiros, indicando o caminho a ser seguido.

A escolha do método para a realização deste trabalho foi o de pesquisa-ação, pela necessidade de envolvimento e participação dos colaboradores da Prefeitura Municipal de Sananduva juntamente com os demais agentes envolvidos neste trabalho.

A metodologia deste trabalho foi dividida em três etapas, conforme apresentado na Figura 5 a seguir.

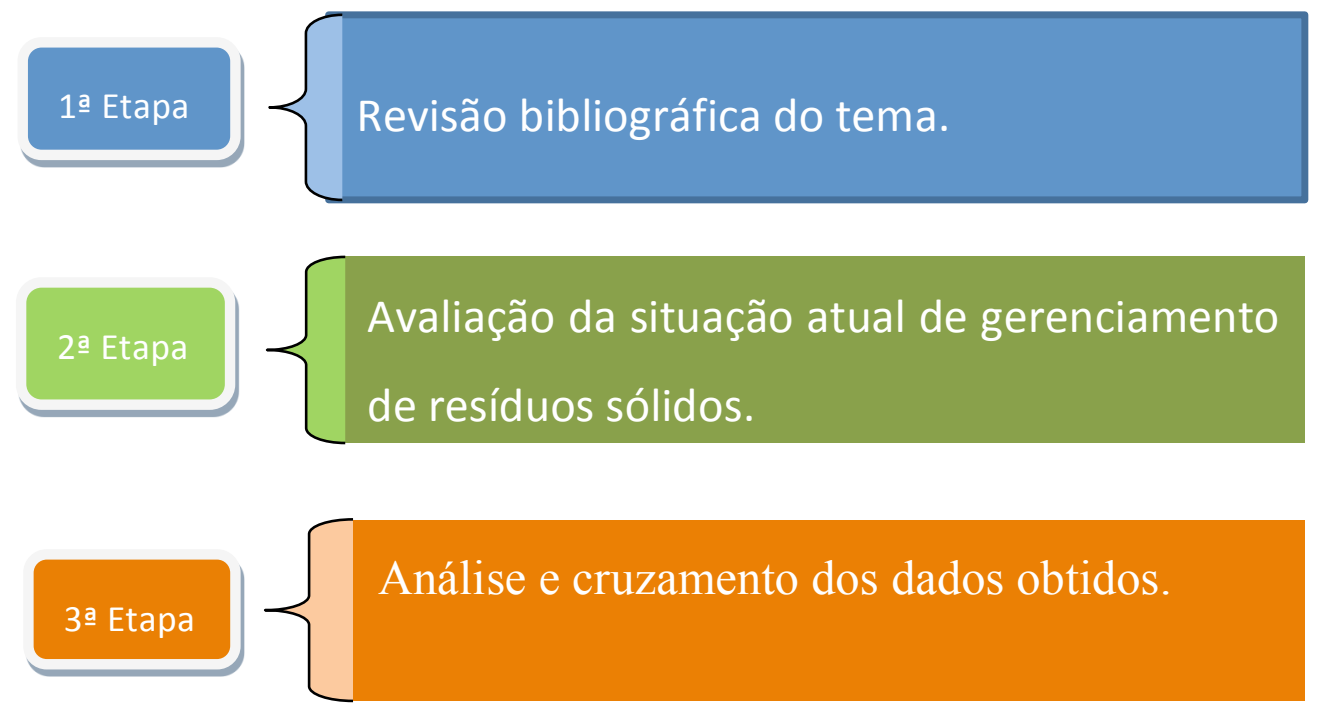

Figura 5: Etapas metodológicas. Fonte adaptado de Lakatos \& Marconi (1991) 
A primeira etapa deu-se por meio de análises em publicações, livros, monografias, artigos, citações, com o objetivo de coletar o maior número de informações sobre o assunto.

A segunda etapa, as atividades realizadas foram relativas ao manejo dos RSU, contemplando geração, coleta e de tratamento e disposição final de RSU, as quais foram feitas por meio de visita técnica e registros fotográficos.

A terceira etapa fez-se a análise e cruzamento dos dados obtidos nas etapas anteriores para formulação do corpo textual, propostas e resultados, por meio de literatura, gráficos e tabelas.

\section{RESULTADOS E DISCUSSÕES}

\section{1 Área de estudo}

O município de Sananduva ocupa um lugar de destaque entre os municípios da microrregião do Nordeste do Estado do RS, localizado nos Campos de Cima da Serra, Região Nordeste do Estado do RS, distante $360 \mathrm{~km}$ de Porto Alegre, capital do RS, abrange uma área de 504, $549 \mathrm{Km}^{2}$ (IBGE 2010 e 2014), de posição geográfica privilegiada. Na Figura 6, podemos observar a localização do município de Sananduva.

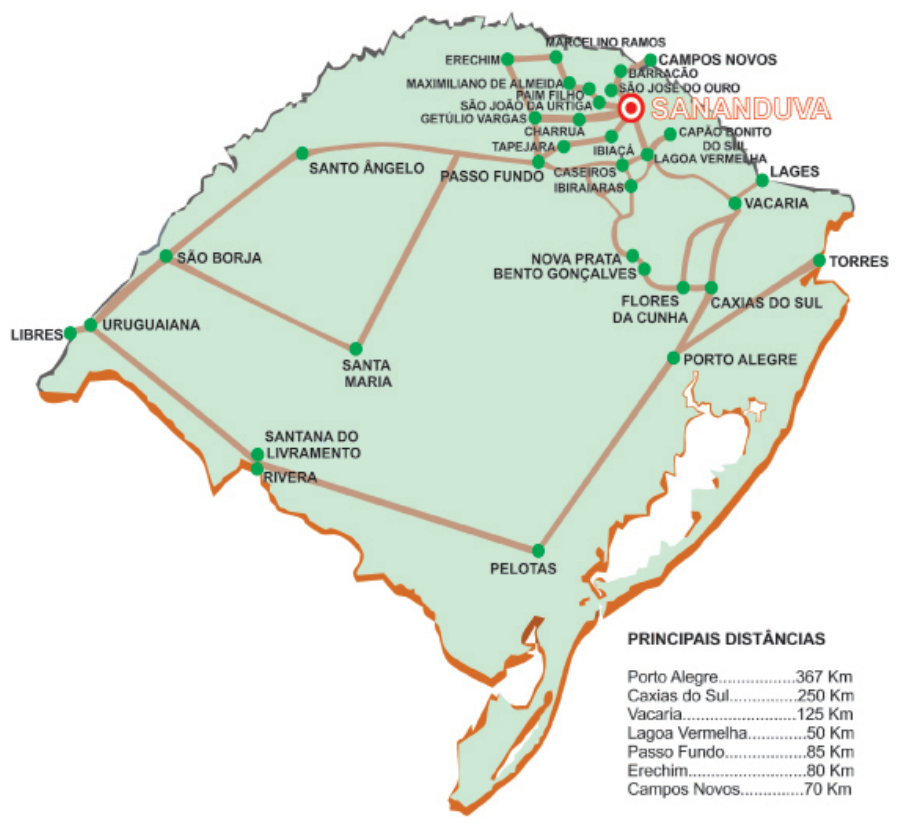

Figura 6: Mapa de localização do município de Sananduva. Fonte: Secretaria Municipal de Agricultura (2015).

Segundo os dados do IBGE (2010 e 2014), o município de Sananduva possui uma população de 15.373 habitantes, sendo 10.811 habitantes residentes na zona urbana e 4.562 habitantes residente na zona rural do município, verificado na Tabela 2. 
Tabela 2: População Urbana e Rural de Sananduva em 2010 - RS.

\begin{tabular}{|c|c|c|}
\hline Descrição & Ano & Município \\
\hline População Rural & 2010 & $4.562(30 \%)$ \\
\hline População Urbana & 2010 & $10.811(70 \%)$ \\
\hline População Total & 2010 & $15.373(100 \%)$ \\
\hline
\end{tabular}

Fonte: IBGE (2010 e 2014).

A principal atividade econômica está ligada a agricultura e a pecuária, onde o cooperativismo e a agroindústria ocupam um papel muito importante no desenvolvimento econômico. A industrialização da madeira e a metalurgia também se destacam na formação do Produto Interno Bruto (PIB). Além do comércio e a prestação de serviços, nas mais diferentes atividades profissionais.

A evolução do número de habitantes e as taxas de crescimento populacional, a partir das séries históricas de registros de 1991, 1996, 2000, 2007 e 2010, conforme Tabela 3, apresentam o aumento populacional médio de $0,32 \%$ ao ano.

Tabela 3: Séries históricas do número de habitantes de Sananduva- RS.

\begin{tabular}{c|c}
\hline ANO & HABITANTES \\
\hline $\mathbf{1 9 9 1}$ & 14.448 \\
$\mathbf{1 9 9 6}$ & 14.733 \\
$\mathbf{2 0 0 0}$ & 14.744 \\
$\mathbf{2 0 0 7}$ & 14.714 \\
$\mathbf{2 0 1 0}$ & 15.373 \\
\hline
\end{tabular}

Fonte: IBGE (2010 e 2014).

\subsection{Diagnóstico da situação atual dos RSU em Sananduva}

Conforme a Tabela 4 e Figura 7, entre os meses set/2012 até ago/2013, o município de Sananduva gerou $3.577 .440 \mathrm{~kg}$ de RSU, o que representa uma média de $298.120 \mathrm{~kg} / \mathrm{mês}$ e 9.937 $\mathrm{kg} /$ dia. De acordo com o IBGE (2010 e 2014), a população urbana atual do município é de 10.811 habitantes, o que representa uma geração de 0,919 kg.hab¹. $\mathrm{d}^{-1}$.

Em analogia com a geração média per capita do RS e Brasil que são de 0,761 e 1,041 $\mathrm{kg} \cdot \mathrm{hab}^{-1} \cdot \mathrm{d}^{-1}$ respectivamente para o mesmo período, a população de Sananduva produz 0,158 $\mathrm{kg} \cdot \mathrm{hab}^{-1} \mathrm{dia}^{-1}$ a mais que a média do RS e $0,122 \mathrm{~kg} \cdot \mathrm{hab}^{-1} \cdot \mathrm{d}^{-1}$ a menos que a média nacional, (ABRELPE, 2013). Esta diferença pode estar relacionada devido às características da população, indústria e produto interno bruto. 
Tabela 4: Quantidade total de geração de RSU em Sananduva/RS, para o período de set/2012 a ago/2013.

\begin{tabular}{c|c}
\hline Quantidade de RSU Gerado em Sananduva 2012/2013 \\
\hline Meses & Total Kg \\
\hline Set/12 & 291.320 \\
Out/12 & 278.770 \\
Nov/12 & 260.530 \\
Dez/12 & 310.800 \\
Jan/13 & 278.090 \\
Fev/13 & 224.330 \\
Mar/13 & 343.710 \\
Abr13 & 323.880 \\
Mai/13 & 337.830 \\
Jun/13 & 293.240 \\
Jul/13 & 327.580 \\
Ago/13 & 307.360 \\
\hline Total & $\mathbf{3 . 5 7 7 . 4 4 0}$ \\
\hline
\end{tabular}

Fonte: Secretaria da Fazenda de Sananduva (2015).

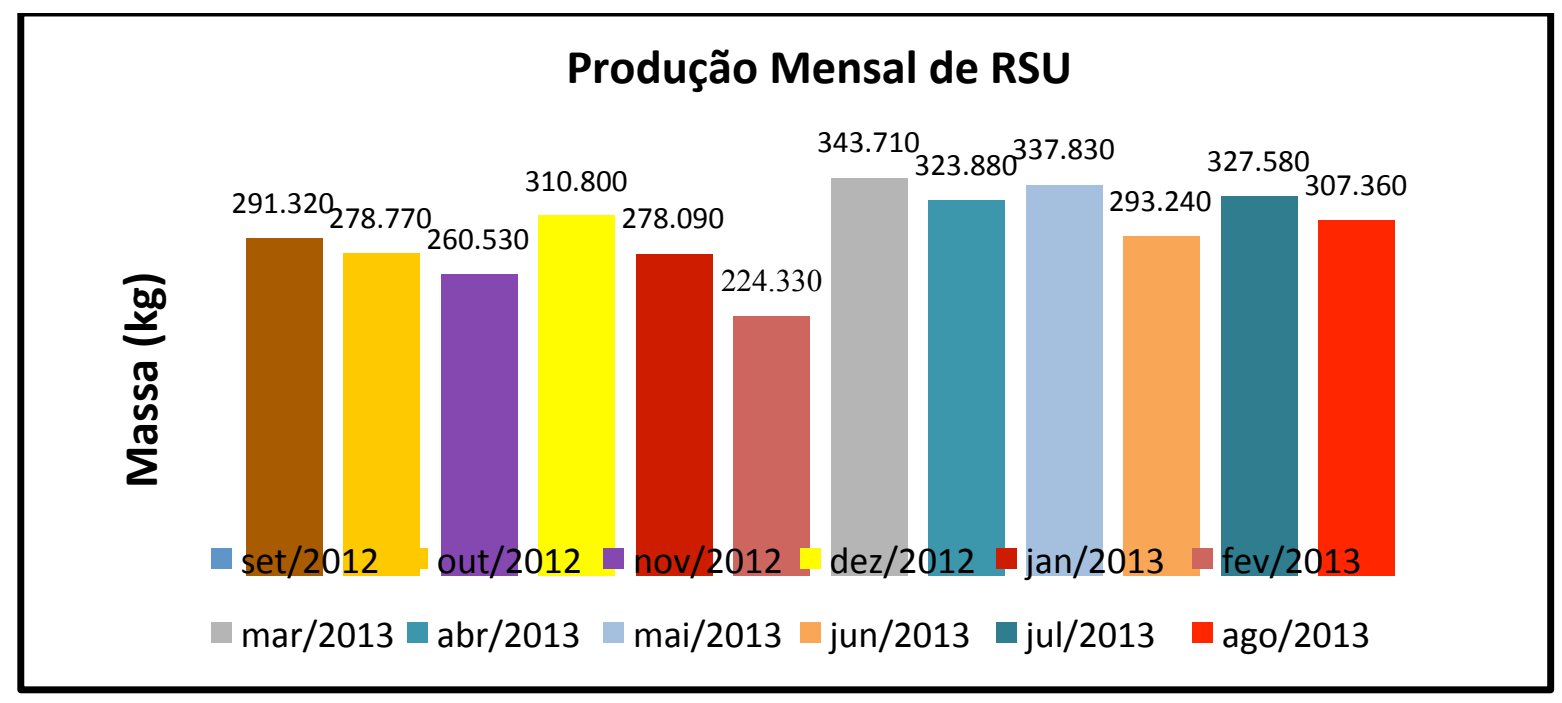

Figura 7: Quantidade Mensal de RSU produzidos pela população urbana do município de Sananduva/RS, no período de set/2012 a ago/2013. Fonte autores (2015).

A partir do segundo semestre de 2012, o transporte e a destinação final dos Resíduos Sólidos Urbanos passaram a ser de responsabilidade da empresa contratada. Assim, os resíduos passaram a ser destinados ao Aterro Sanitário com licenciamento ambiental em vigor, pertencente a empresa CRI - Coleta, Reciclagem e Industrialização de Lixo LTDA, situado em Ipumirim/SC, a 160 quilômetros de Sananduva/RS, em uma área total de $26.549 \mathrm{~m}^{2}$, os quais estão sendo utilizados na operação do aterro. Com uma capacidade para receber $40 \mathrm{t} / \mathrm{dia}$ de resíduos, o aterro tem uma vida útil estimada em 20 anos.

Os custos envolvidos no atual gerenciamento de RSU do Município de Sananduva/RS pode ser verificado na tabela 5, representam um custo médio mês de $R \$ 45.443,25$, o que representa 
um custo $\mathrm{R} \$ \mathrm{0,14} \mathrm{hab}^{-1} \cdot \mathrm{d}^{-1}$. Destacando que estes recursos estão envolvidos ao processo de coleta, transporte e destinação final do RSU.

Tabela 5: Custos totais mensais envolvidos na coleta, transporte e destinação final dos resíduos sólidos de Sananduva.

\begin{tabular}{c|c}
\hline Valores Mensais Gastos com a Destinação Final dos RSU \\
\hline Meses & Total (R\$) \\
\hline Setembro & $44.854,04$ \\
Outubro & $37.335,76$ \\
Novembro & $40.112,62$ \\
Dezembro & $47.863,20$ \\
Janeiro & $42.827,86$ \\
Fevereiro & $34.546,82$ \\
Março & $52.931,34$ \\
Abril & $49.877,52$ \\
Maio & $52.030,44$ \\
Junho & $45.158,96$ \\
Julho & $50.447,05$ \\
Agosto & $47.333,44$ \\
\hline Total Anual & $\mathbf{5 4 5 . 3 1 9 , 0 5}$ \\
\hline
\end{tabular}

Fonte: Secretaria da Fazenda de Sananduva (2015).

A partir destes resultados obtidos, são necessários estudos e projetos alternativos de modo a possibilitar uma atividade de gerenciamento autossustentável dos RSU, devido alto custo da Gestão de RSU do município de Sananduva/RS. Este planejamento deve incluir redução de gastos e aumento de renda em virtude do aproveitamento de materiais residuais passíveis de reciclagem.

\subsection{Central de Triagem}

Até o fim da década de 90 do século passados, os resíduos gerados no município de Sananduva eram dispostos em locais inadequados, sem nenhum cuidado técnico e condições de sanidade. No início dos anos 2000 foi construída e implantada uma Unidade de Triagem e Classificação de RSU com uma área de $42.000 \mathrm{~m}^{2}$, verificada na Figura 8 . O processo de triagem dos RSU foi implementado de acordo a legislação pertinente e Licença de Operação vigente no período, emitida pelo órgão estadual ambiental de fiscalização, até meados de julho de 2005. 


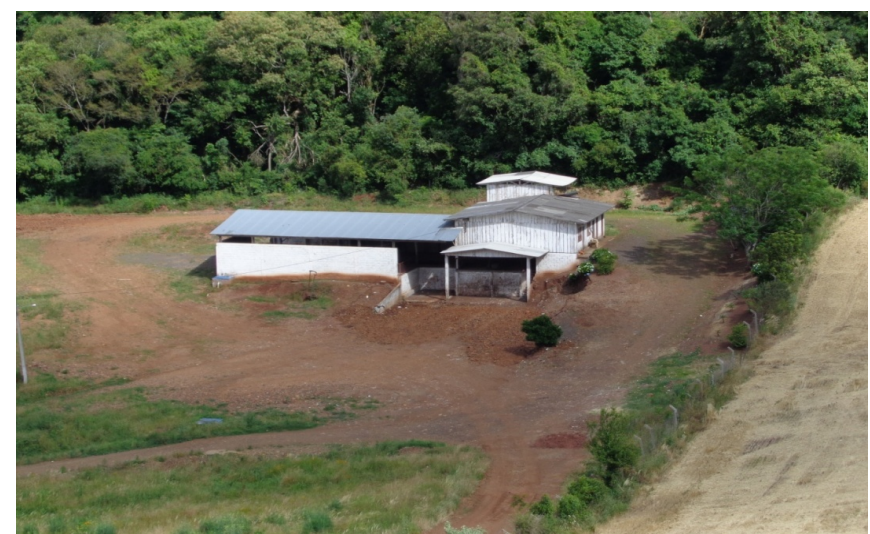

Figura 8: Vista superior da Usina de Triagem atual em fase de readequação. Fonte autores (2015).

Em 2006, foi realizado um projeto de adequação do aterro sanitário e da unidade de triagem e classificação dos RSU de Sananduva, pela necessidade de implantação de uma nova forma de operação do local de destinação final dos resíduos sólidos urbanos no município, uma vez que os critérios técnicos exigidos não são atendidos em sua plenitude.

O projeto de adequação foi concebido de acordo com as ABNT NBR 12.980/1993 e 8419/1992, e encontra-se em fase de regularização junto ao órgão ambiental licenciador.

\subsection{Aterro Sanitário}

O objetivo principal do aterro sanitário é operar de modo a fornecer proteção ao meio ambiente, evitando a contaminação do solo e das águas subterrâneas pelo chorume e lixiviado resultante da decomposição da matéria orgânica, além de impedir o lançamento de gases nocivos ao meio ambienta oriundo principalmente processos anaeróbios decomposição de resíduos.

Em 2006, o município de Sananduva propôs e executou o projeto de adequação do Aterro Sanitário Municipal (ASM), de acordo com ABNT NBR 8.419/1992, o qual foi construído sobre um antigo lixão, após processo de descontaminação da área. A célula ASM apresenta uma capacidade volumétrica de $10.146 \mathrm{~m}^{3}$ de resíduo compactado, sendo o fator de compactação de $0,7 \mathrm{t} / \mathrm{m}^{3}$ (Bidone \& Povinelli 1999), perfazendo uma vida útil de 53 meses, ou seja, 4,4 anos, para uma projeção subdimensionada de geração diária de RSU de $4.422 \mathrm{~kg} \cdot \mathrm{d}^{-1}$ ou de $0,434 \mathrm{~kg} \cdot \mathrm{hab}^{-1} \cdot \mathrm{d}^{-1}$.

A construção de uma célula de aterramento foi realizada com a base e as laterais impermeabilizadas, com argila compactada e geomembrana PEAD, a inclusão de drenos para a captação de líquidos gerados e percolados no interior da célula de aterramento; tubulações para a drenagem dos gases gerados: melhoria nos acessos internos: drenagem pluvial ao entorno do ASM e isolamento da área. A Figura 9 apresenta a estrutura da célula do ASM. 


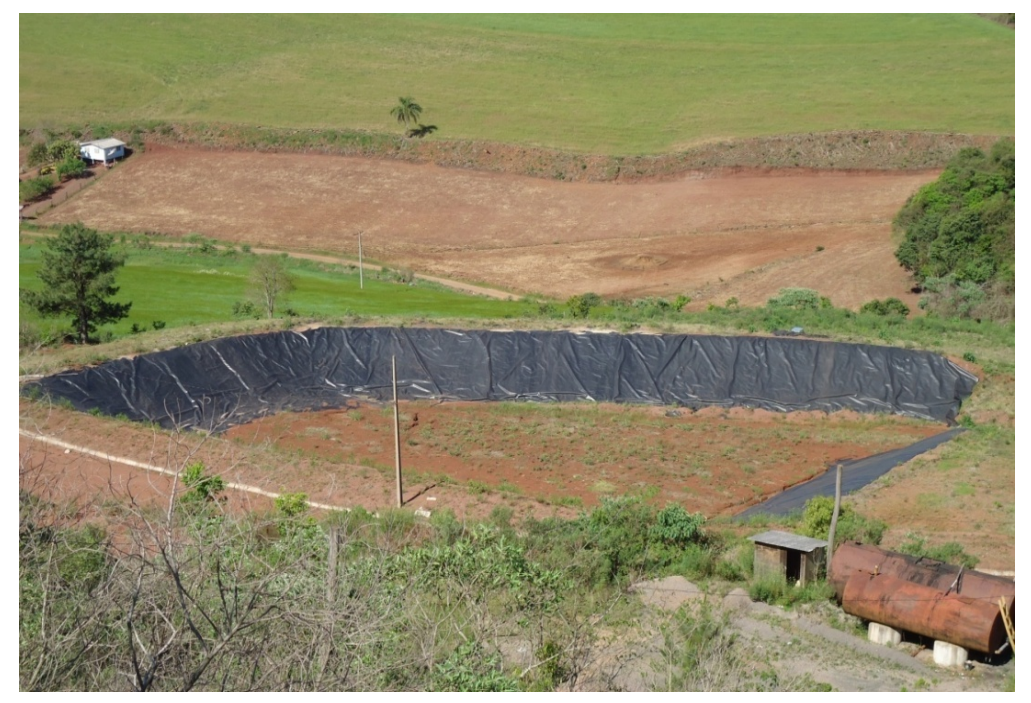

Figura 9: Célula do atual Aterro Sanitário de Sananduva. Fonte autores (2015).

Atualmente o ASM possui Licença de Operação vigente, emitida pela Fundação Estadual de Proteção Ambiental - FEPAM (LO n 5063/2004-DL), mas ainda não se encontra em operação efetiva, por falta de mão de obra e recursos para implantação.

\subsection{Prognósticos a Gestão de RSU}

Conforme já foi descrito o ASM foi projetado em 2006 para uma vida útil de 4 anos e aproximadamente 5 meses, para uma produção diária de $0,434 \mathrm{~kg} \cdot \mathrm{hab}^{-1} \cdot \mathrm{d}^{-1}$. Considerando a produção diária apresentada neste trabalho nos períodos de set/2012 a ago/2013 é de 0,919 $\mathrm{kg} \cdot \mathrm{hab}^{-1} \cdot \mathrm{d}^{-1}$, ou seja, com as dimensões projetadas o ASM teria sua capacidade esgotada em menos 2 anos.

Com isto se verifica a necessita da implantação de processos ou iniciativas que viabilizem o aumento da vida útil do atual ASM, com diminuição de geração ou o incentivo à processos de reuso e reciclagem. A proposta de uso de processos como compostagem, coleta seletiva, logística Reversa e Incineração, poderiam permitir o aumento da vida útil do aterro sanitário, ou seja, o aproveitamento adequado dos materiais descartados dito como lixo.

\subsubsection{Estratégias para reduzir o envio de RSU para ASM}

O processo de incineração tem como princípio a conversão de RSU, através do processo de combustão, em energia térmica. A incineração resulta na redução de volume e massa do resíduo, através da queima controlada, que apesar da elevada eficiência de conversão, produz rejeitos (cinzas) que podem dispostos em aterros sanitários adequados, como no caso do ASM de Sananduva. A incineração poder representar numa redução de massa entre 85 e 95\% (GRIPP, 1998).

No processo de incineração podemos apontar as vantagens e limitações, dentre as vantagens da combustão de RSU é a redução drástica do volume e massa a ser descartado, redução da amplitude do impacto ambiental, recuperação de energia, aumento da vida útil dos 
aterros sanitários e destoxificação; e entre as limitações destacamos: custo elevado de operação e manutenção, mão-de-obra qualificada, problemas operacionais, restrição quanto aos limites de emissão de componentes tóxicos que são lançados na atmosfera.

A compostagem é definida como o ato ou a ação de transformar os resíduos orgânicos, através de processos físicos, químicos e biológicos, em uma matéria biogênica mais estável e resistente à ação das espécies consumidoras (Lima, 2004). O resultado final é o composto, excelente condicionador orgânico dos solos. A compostagem é feita em pátios especialmente preparados, sendo o material orgânico disposto em leiras (montes) que operam por reviramento ou por aeração forçada (Barros, 2012).

A compostagem pode ser utilizada como uma alternativa para transformação dos $100 \%$ resíduos orgânicos sólidos, integrada num sistema de reciclagem de materiais ou como único sistema de tratamento da fração orgânica dos resíduos (Russo, 2003). Para isto, deve-se fomentar nas organizações a coleta seletiva ou logística reversa de $100 \%$ de matérias que possam ser reutilizados, reciclados ou recuperação como matérias-primas ou transformação em energia (Kiehl, 1998).

Conforme Tabela 6 e Figura 3, para a geração de RSU é de 3.577,4 t/ano no município de Sananduva no período de set/2012 a ago/2013, com a proposta de compostagem é possível eliminar aproximadamente $51 \%$ do total de RSU, formados de matéria orgânica, que não seriam dispostos no ASM. Com a implantação da coleta seletiva e aperfeiçoamento da logística reversa seria possível reciclar ou reutilizar aproximadamente $32 \%$, constituído de materiais recicláveis ou potencialmente reutilizáveis.

Tabela 6: Propostas de aumento da vida útil do ASM.

\begin{tabular}{c|c|c|c}
\hline PROPOSTA & COMPOSIÇÃO (\%) & TIPO & $\begin{array}{c}\text { PRODUÇÃO } \\
\text { (t/ano) }\end{array}$ \\
\hline Compostagem & 51 & Matéria Orgânica & $1.824,4$ \\
$\begin{array}{c}\text { Coleta Seletiva/Logística } \\
\text { Reversa }\end{array}$ & 32 & Recicláveis & $1.144,7$ \\
Incineração & 17 & Diversos & 597,4 \\
\hline
\end{tabular}

Fonte: Adaptado de ABRELPE 2012. Fonte autores (2015).

A proposta de incineração neste trabalho pode ser aplicada a $17 \%$ dos RSU produzidos. Conforme Gripp (1998) o processo de incineração tem a capacidade de reduzir em torno de $90 \%$ da massa de RSU, o que permitiria a diminuição da massa dos resíduos diversos, apresentada na Tabela 8, de 597 t/ano para 59,7 t/ano de rejeitos a serem depositados no ASM.

A partir das propostas sugeridas e projeções de geração, tratamento e disposição final de RSU no município de Sananduva, onde o aterro sanitário, projetado em 2006 para o tempo de vida útil de 4,4 anos para o armazenamento de RSU. Com a inclusão dos processos indicados neste artigo poderia condições ótimas de operação obter um aumento da vida útil do ASM por 
um período aproximado de 119 anos (considerando fator de compactação de $0,7 \mathrm{~kg} / \mathrm{m}^{3}$ de RSU, (Bidone \& Povinelli 1999), o que permitiria uma gestão de RSU em longo prazo.

É evidente que são condições ótimas de operação, que dificilmente são alcançáveis, mas considerando que a implementação destas atividades devem estar de acordo com a normas e legislações vigentes pelos órgãos ambientais de fiscalização, são elevadas a chances de aumento da vida útil do ASM de Sananduva pelo período mínimo de 20 anos como conforme preconiza as normas vigentes para construção de aterros sanitários.

\section{CONCLUSÕES}

A partir dos resultados obtidos é de suma importância no intuito de promover uma mudança de hábitos e atitudes, pois é na origem que se encontra um dos maiores problemas quanto a geração, separação e coleta de resíduos, representando da disposição de RSU em locais inadequados, trazendo com isso diversos problemas sociais e ambientais. A sociedade quando educada, informada e instruída, exerce papel fundamental diante de problemas de ordem social e ambiental, despertando para a realidade e responsabilidade de cada indivíduo, neste contexto a educação ambiental torna-se ferramenta de grande importância pelas várias nuances a possibilidades de trabalhar tanto com crianças, jovens ou adultos.

Os resultados encontrados demonstram também a necessidade de inserção de novas técnicas de gerenciamento de RSU. Abordam-se formas de tratamento, tais como a compostagem, coleta seletiva e a incineração. A compostagem e a coleta seletiva visam o aproveitamento dos resíduos sólidos orgânicos e materiais recicláveis e, consequentemente, a redução de seu volume que seria disposto no aterro sanitário, uma vez que se constatou uma grande oferta de material orgânico e reciclável passível de aproveitamento e que vêm sendo desperdiçado.

A incineração seria tecnicamente viável como uma possível alternativa para auxiliar no gerenciamento dos RSU, indicada principalmente para os resíduos da área da saúde, industriais e perigosos. É evidente a necessidade de caracterização dos resíduos a serem incinerados, a fim de se obter melhor domínio da combustão e controle dos rejeitos.

Contudo, a questão dos RSU deve ser encarada como um problema de toda a sociedade. No caso do município de Sananduva/RS, os métodos sugeridos utilizados de tratamento e destinação final de RSU para obter um resultado satisfatório é necessária implantação em conjunto a coleta seletiva/logística reversa, compostagem e incineração, como alternativas tecnicamente viáveis buscando um aumento significativo da vida útil do atual ASM.

\section{REFERÊNCIAS}

ABNT NBR 8.419/1992: Apresentação de Projetos de Aterros Sanitários de Resíduos Sólidos Urbanos.

ABNT NBR 12.980/1993: Coleta, varrição e acondicionamento de resíduos sólidos urbanos. Rio de Janeiro.

ABNT NBR 10.004/2004: Resíduos Sólidos - Classificação. 
ABRELPE. Panorama dos Resíduos Sólidos no Brasil, 2012. 116 p. PDF. Recuperado em 15 de setembro de 2014, de <http://www.abrelpe.org.br/Panorama/panorama2012.pdf/>.

ABRELPE. Panorama dos Resíduos Sólidos no Brasil, 2013. 114 p. PDF. Recuperado em 15 de setembro de 2014, de <http://www.abrelpe.org.br/Panorama/panorama2013.pdf/>.

BARROS, R. T. V. Elementos de Gestão de Resíduos Sólidos. Editora Tessitura: Belo Horizonte, 424 p. 2012.

Lei n. 12.305, de 02 de agosto de 2010. Institui a Política Nacional de Resíduos Sólidos; altera a Lei no 9.605, de 12 de fevereiro de 1998; e dá outras providências. Diário Oficial da União, Brasília, no 147, p. 303 de ago. 2010. Recuperado em 03 de outubro de 2015, de http://www.planalto.gov.br/ccivil_03/_ato2007-2010/2010/lei/l12305.htm

Lei $n$. lei, de 05 de janeiro de 2007. Estabelece diretrizes nacionais para o Saneamento Básico; altera as Leis $\mathrm{n}^{\mathrm{os}}$ 6.766, de 19 de dezembro de 1979, 8.036, de 11 de maio de 1990, 8.666, de 21 de junho de 1993, 8.987, de 13 de fevereiro de 1995; revoga a Lei $n^{\circ}$ 6.528, de 11 de maio de 1978; e dá outras providências. Diário Oficial da União, Brasília, p. 308 de janeiro de 2007. Recuperado em 04 de outubro de 2015, de http://www.planalto.gov.br/ccivil_03/_ato20072010/2007/lei/l11445.htm

BIDONE, F. R. A. \& POVINELLI, J. Conceitos Básicos de Resíduos sólidos. São Carlos: EESC/USP, 1999.

CALDERONI, S. Os bilhões perdidos no lixo. 4a ed. São Paulo. Humanitas Editora. 346 p. 2003.

CONSONI, A.J. \& GONZALEZ, C. C. C. Lixo municipal: manual de gerenciamento integrado. 2a ed. São Paulo. Instituto de Pesquisas Tecnológicas - IPT/ Compromisso Empresarial para Reciclagem - CEMPRE, cap. 8, p. 317 - 342, 2000.

GRIPP, W. G. (1998). Aspectos técnicos e ambientais da incineração de resíduos sólidos urbanos: considerações sobre a proposta para São Paulo. Dissertação de estrado em Hidráulica e Saneamento, Escola de Engenharia de São Carlos, Universidade de São Paulo, São Carlos, SP, Brasil.

IBGE. Sananduva. Estatística, população, estimativa 2010. Recuperado em 9 de novembro de 2014, <http://www.ibge.gov.br/home/estatistica/populacao/estimativa2014/estimativa_tcu.shtm/ $>$.

IBGE. Censo Demográfico 2010. Recuperado em 10 de novembro de 2014, de <http://cidades.ibge.gov.br/painel/painel.php?codmun=431660>.

KIEHL, E.J., Manual de Compostagem: maturação e qualidade do composto. Piracicaba, SP, Divisão de Biblioteca e Documentação "Luiz de Queiros" /USP, 1998.

LAKATOS, E.M. \& MARCONI, M. A. Fundamentos de Metodologia Cientifica. São Paulo: Atlas, 270 p. 1991.

LIMA, L. M. Q. Lixo Tratamento e Biorremediação. 3ạ ed. Hemus. São Paulo, 2004.

MAZZER , C. \& CAVALCANTI, O.A. Introdução a Gestão Ambiental de Resíduos. Informa, v.16, no 11-12, 2004.

Ministério do Meio Ambiente (2011). Guia para elaboração dos Planos de Gestão de Resíduos Sólidos - Brasília - DF, 2011. 289 p. Recuperado em 21 de setembro de 2015, de 
<http://www.mma.gov.br/estruturas/srhu_urbano/_arquivos/guia_elaborao_plano_de_gest o_de_resduos_rev_29nov11_125/>.

ZVEIBIL, V. Z.; MONTEIRO, J. H. P.; FigueiRedo, C. E. M.; MAGAlhÃES, A. F.; MelO, M. A. F.; BRITO, J. C. X.; ALMEIDA, T. P. F. \& MANSUR, G. L. Manual de gerenciamento integrado de resíduos sólidos. Rio de Janeiro: IBAM, 204p. 2001. Recuperado em 5 de outubro de 2014, de <http://www.resol.com.br/cartilha4/manual.pdf/>.

RUSSO, M. A. T. (2003). Tratamento de resíduos sólidos. Tese de doutorado em Engenharia Agrícola, Universidade de Coimbra. Faculdade de Ciência e Tecnologia, Departamento de Engenharia Civil, Coimbra, Portugal.

SANDRINI, N. S (2005). Estudo das características próprias da coleta seletiva informal. Monografia Especialização em Gestão de Recursos Naturais, Universidade do Extremo Sul Catarinense, Criciúma, SC, Brasil. 